\title{
Ngồi văn phòng có cần thiết phải đeo thẻ nhân viên?
}

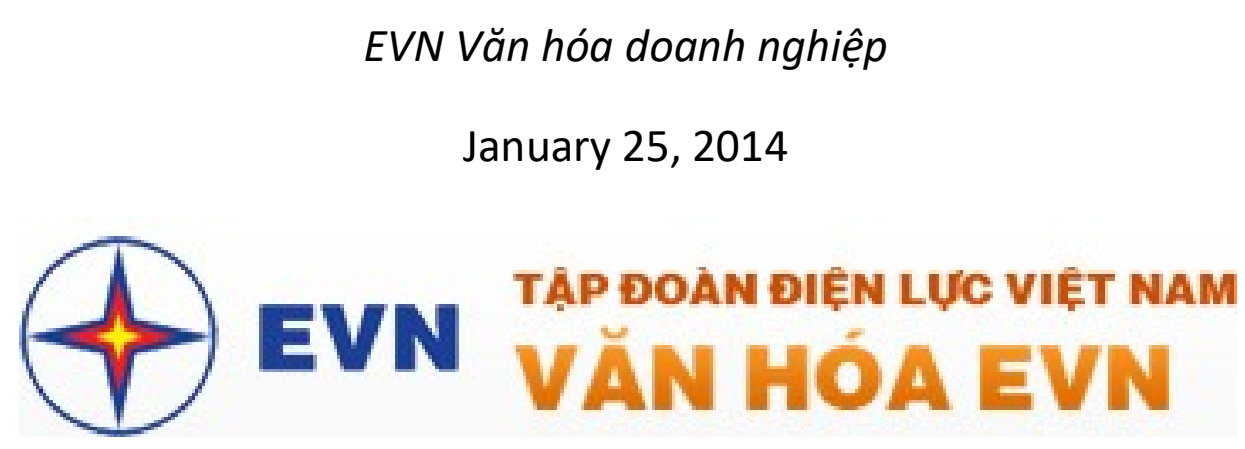

https://vanhoa.evn.com.vn/d3/faqs/Ngoi-van-phong-co-can-thiet-phai-deo-thenhan-vien-394.aspx 


\section{Ngồi văn phòng có cần thiết phải đeo thẻ nhân viên?}

Công việc của tôi ít khi phải gặp gỡ khách hàng, thường chỉ ngồi làm việc tại văn phòng. Nhưng công ty yêu cầu $100 \%$ nhân viên đi làm phải đeo thẻ nhân viên và mặc đồng phục. Nhân viên nào quên đeo thẻ thì bị khiển trách. Việc mặc đồng phục thì rõ rồi, tuy nhiên tôi muốn việc đeo thẻ nhân viên khi làm việc quan trọng như thế nào trong vấn đề phát triển văn hóa doanh nghiệp.

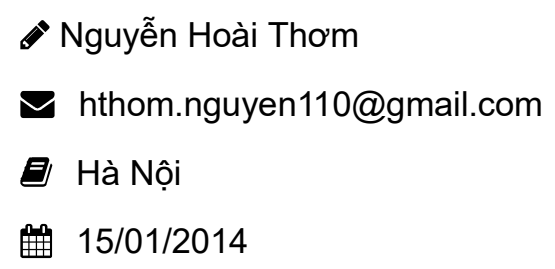

Phản hồi

\section{Trả lời}

Cốt lối của văn hóa doanh nghiệp là tinh thần doanh nghiệp và quan điểm giá trị của doanh nghiệp. Lãnh đạo công ty sẽ rất khó xây dựng văn hóa doanh nghiệp, nếu không truyền đạt được những ích lợi mà văn hóa doanh nghiệp đem lại. Nhân viên cần được giáo dục nhận thức rằng việc đeo thẻ nhân viên, mặc đồng phục là thể hiện sự tự hào là thành viên của công ty, và có ích cho công việc của họ chứ không phải họ mang những thứ đó để quảng cáo.

Cùng với đồng phục, thẻ nhân viên cũng là một phần của văn hóa doanh nghiệp, tạo nên hình ảnh đẹp, chuyên nghiệp trong mắt đối tác, khách hàng. Khi đeo thẻ tên, các nhân viên sẽ luôn tự hào về nghề nghiệp của mình, nâng cao trách nhiệm, ý thức trong công việc. Văn hóa doanh nghiệp bắt đầu từ những điều nhỏ nhất, cụ thể, không chung chung.

(Theo sách "Văn minh làm giàu và nguồn gốc của cải”, Tác giả: TS. Vương Quân Hoàng, NXB: Chính trị quốc gia , Năm xuất bản: 2007) 


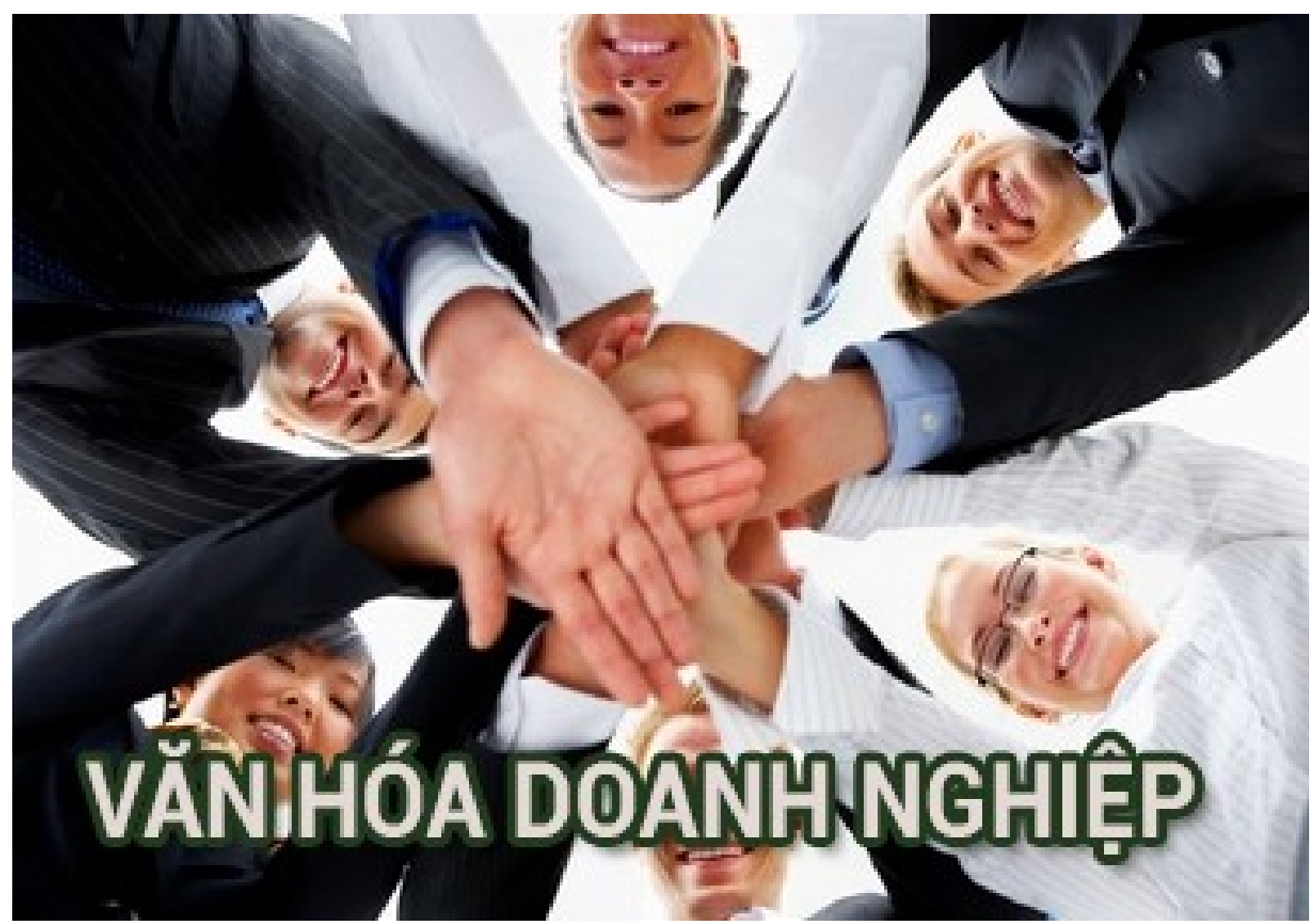

(/c3/pages-c/Van-hoa-doanh-nghiep-6-120.aspx)

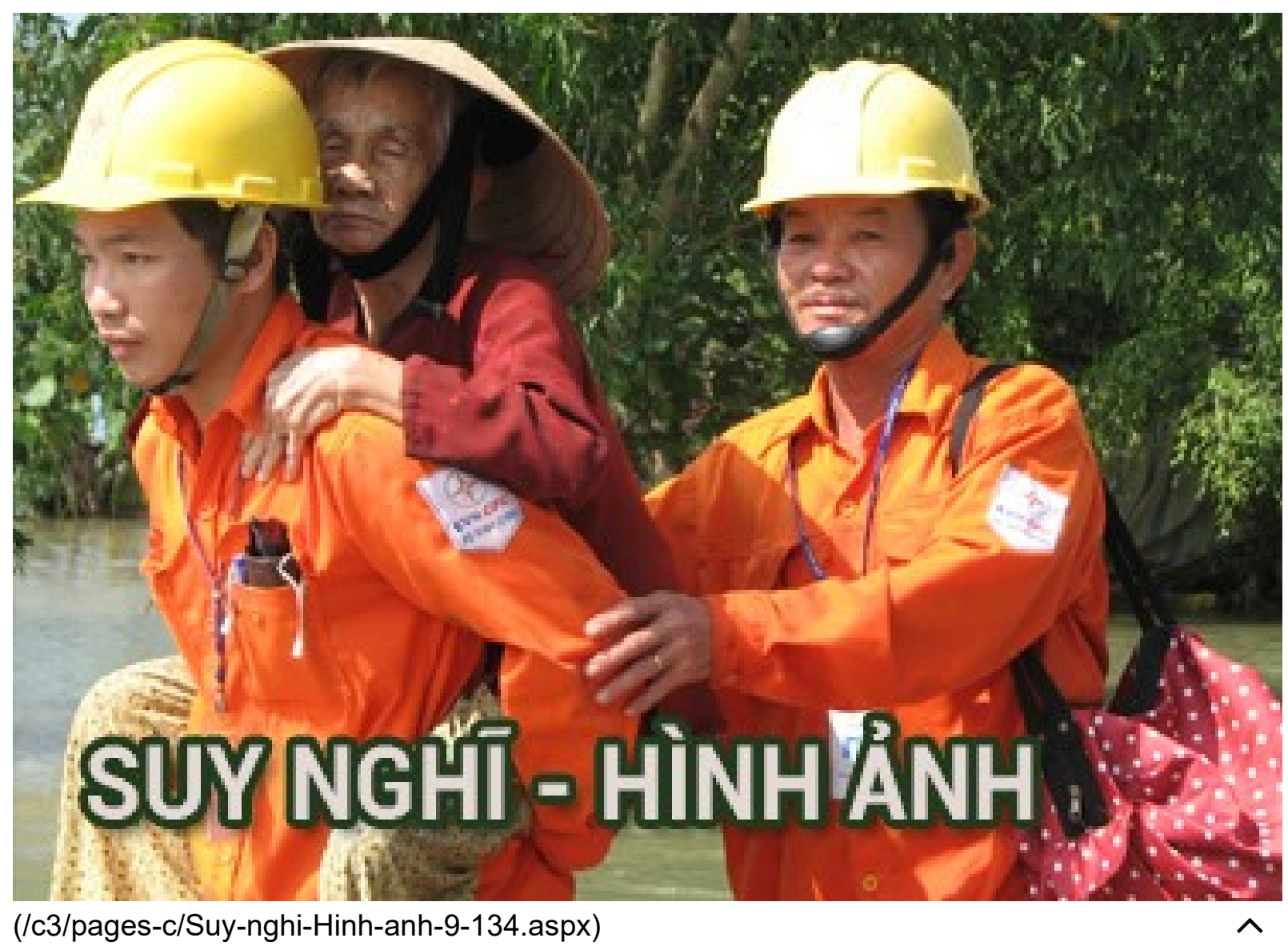




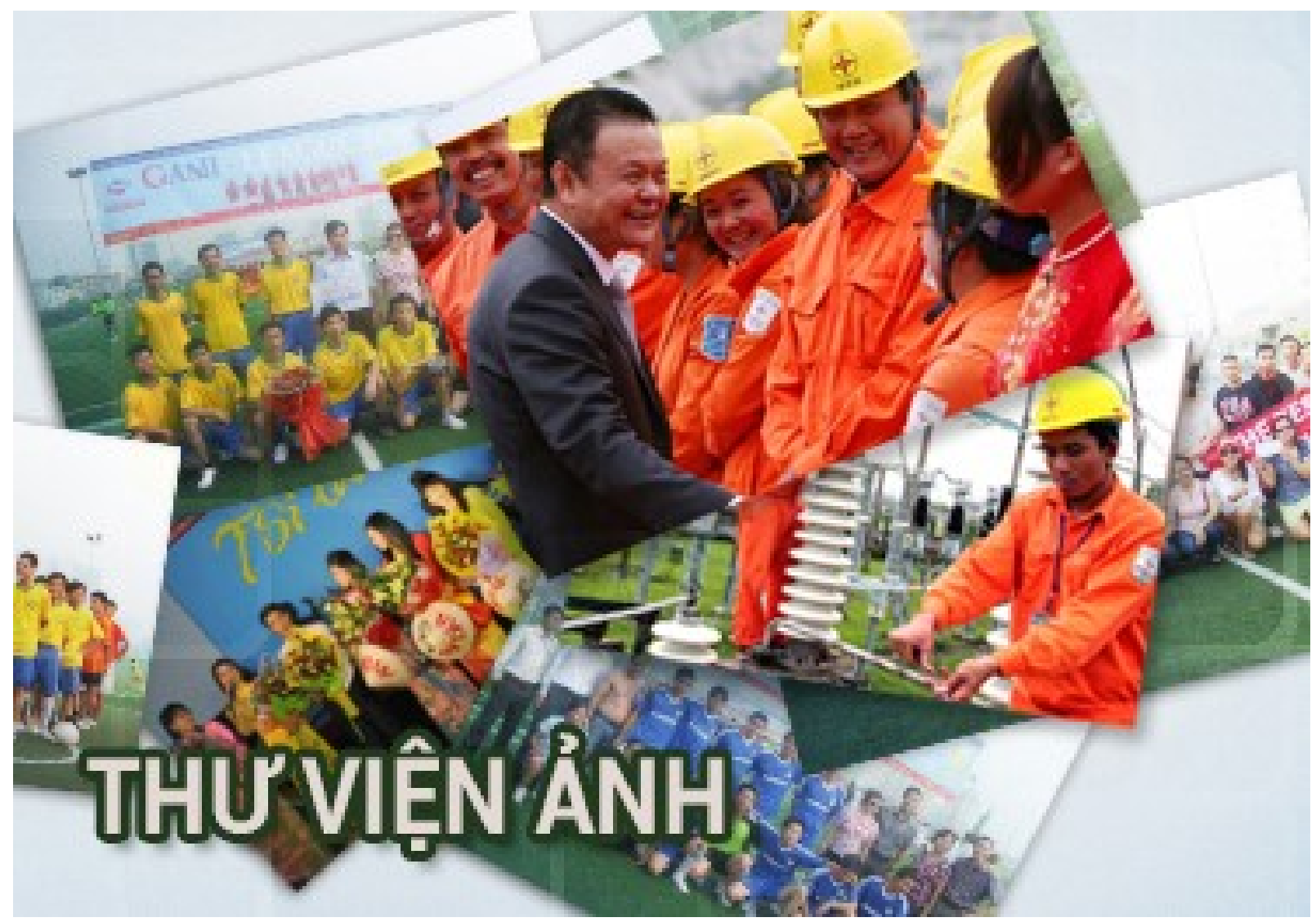

(/thu-vien-anh.aspx)

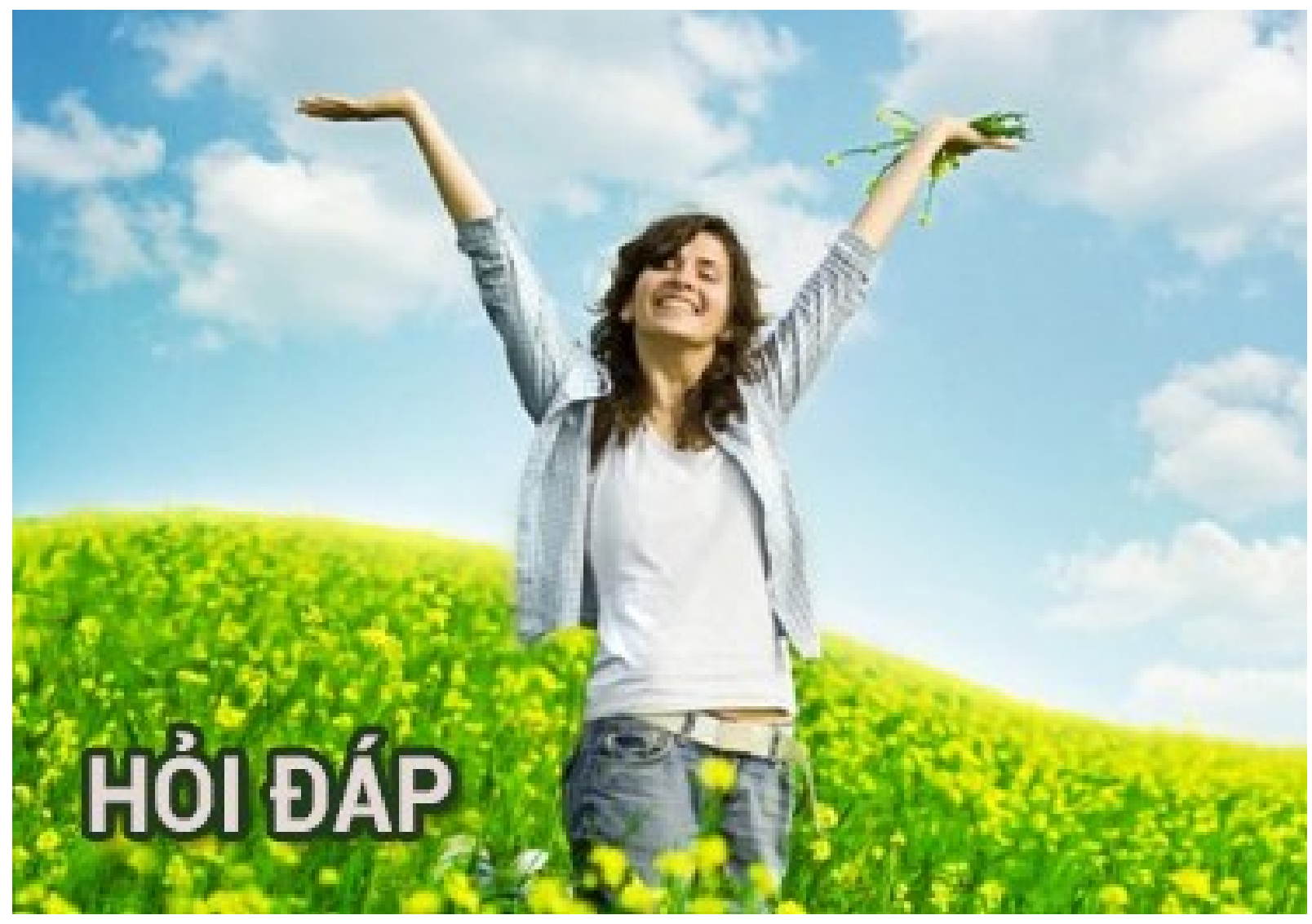

(/c3/faqs-c/Hoi-Dap-5-116.aspx) 


\section{Thư viện ảnh (/thu-vien-anh.aspx)}

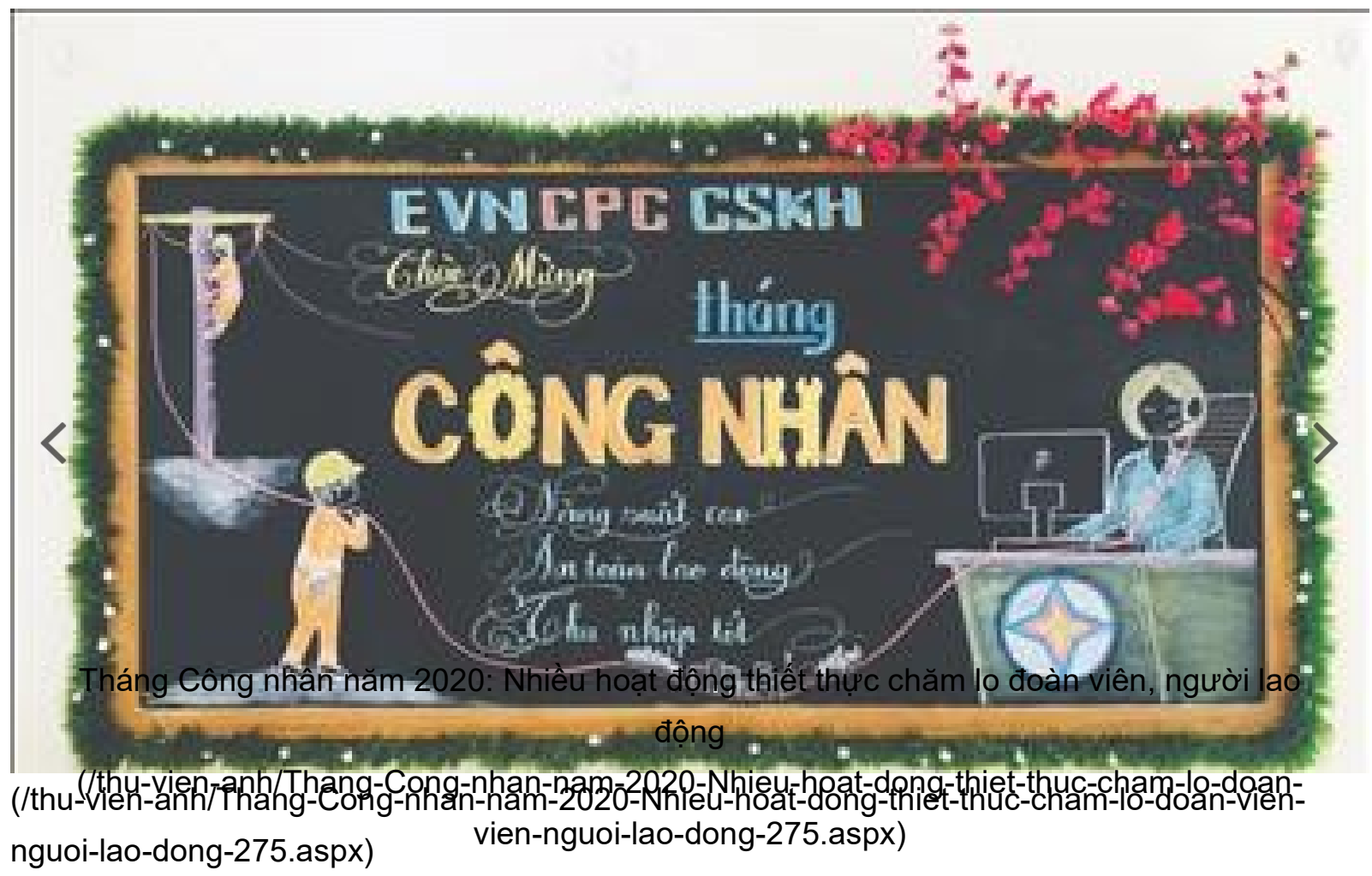

\section{Thế giới văn hóa}

Bản tin văn hóa (/c3/pages-c/Ban-tin-vanhoa-6-117.aspx)

Văn hóa doanh nghiệp (/c3/pages-c/Vanhoa-doanh-nghiep-6-120.aspx)

Văn hóa doanh nhân (/c3/pages-c/Van-hoadoanh-nhan-6-122.aspx)

Tình huống - Thương hiệu (/c3/pagesc/Tinh-huong-Thuong-hieu-6-123.aspx)

Kinh nghiệm và bài học (/c3/pages-c/Kinhnghiem-va-bai-hoc-6-124.aspx)

Giao tiếp ứng xử (/c3/pages-c/Giao-tiepung-xu-6-121.aspx)

\section{Nhịp sống EVN}

Chính sách - Nhân sự (/c3/pages-c/Chinhsach-Nhan-su-7-125.aspx)

Gia đình EVN (/c3/pages-c/Gia-dinh-

EVN-7-126.aspx)

Con người EVN (/c3/pages-c/Con-nguoiEVN-7-127.aspx)

Thư viện ảnh (/thu-vien-anh.aspx)

Thì thầm - Chia sẻ (/c3/pages-c/Thi-thamChia-se-7-131.aspx) 


\section{(C) Bản quyền thuộc về Tập đoàn Điện lực Việt Nam \\ Điện thoại: 024.66946789 * Fax: 024.66946666}

Người chịu trách nhiệm chính: Ông Võ Quang Lâm - Phó Tổng giám đốc Tập đoàn Điện lực Việt Nam

Giấy phép số: 1908/GP-TTĐT do Sở Thông tin và Truyền thông Hà Nội cấp ngày 15/5/2018. Thực hiện: Trung tâm Thông tin Điện lực. Đ/c: Số 11 Cửa Bắc, phường Trúc Bạch, quận Ba Đình, Hà Nội.

Điện thoại: 024.66946731 * Fax: 024.37725192 - Email: banbientapwebevn.eic@evn.com.vn banbientapwebevn.eic@gmail.com

Thiết kế và phát triển bởi EVNICT. Thông tin trích từ trang thông tin điện tử này yêu cầu ghi rõ từ nguồn www.evn.com.vn 
Tài liệu tham khảo:

[1] Đào Duy Anh. (1938). Việt Nam văn hóa sử cương. Quan Hải Tùng Thư, Huế (Imprimerie du Mirador).

[2] Vương Quân Hoàng. (2007). Văn minh làm giàu \& Nguồn gốc của cải. Nxb Chính trị Quốc gia, Hà Nội. 